
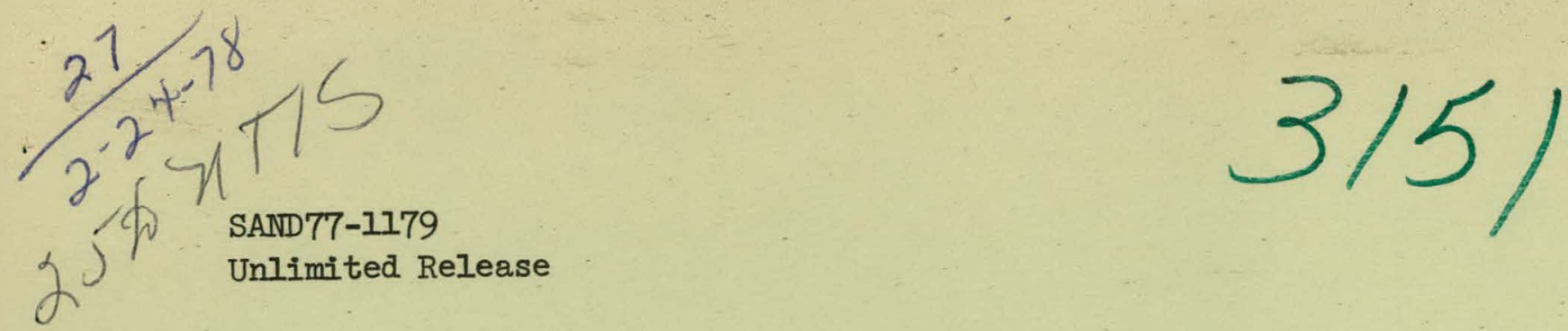

\title{
AN INSTALLATION INDEPENDENT VERSION OF THE SANDIA SCORS PLOT SYSTEM
}

By S. L. Thompson and N. K. Ruiz

Prepared by Sandia Laboratories, Albuquerque, New Mexico 87115

and Livermore, California 94550 for the United States Energy Research

and Development Administration under Contract AT (29-1)-789

Printed January 1978

\section{Sandia Laboratories}




\section{DISCLAIMER}

This report was prepared as an account of work sponsored by an agency of the United States Government. Neither the United States Government nor any agency Thereof, nor any of their employees, makes any warranty, express or implied, or assumes any legal liability or responsibility for the accuracy, completeness, or usefulness of any information, apparatus, product, or process disclosed, or represents that its use would not infringe privately owned rights. Reference herein to any specific commercial product, process, or service by trade name, trademark, manufacturer, or otherwise does not necessarily constitute or imply its endorsement, recommendation, or favoring by the United States Government or any agency thereof. The views and opinions of authors expressed herein do not necessarily state or reflect those of the United States Government or any agency thereof. 


\section{DISCLAIMER}

Portions of this document may be illegible in electronic image products. Images are produced from the best available original document. 
Issued by Sandia Laboraturies, opcrated for the United States Department of Energy by Sandia Corporation.

\section{NOTICE}

This report was prepared as an account of work sponsored by the United States Government. Neither the United States nor the United States Department of Energy, nor any of their employees, nor any of their contractors, subcontractors, or their employees, makes any warranty, express or implied, or assumes any legal liability or responsibility for the accuracy, completeness or usefulness of any information, apparatus, product or process disclosed, or represents that its use would not infringe privately owned rights.

Printed in the United States of America

Available from

National Technical Information Service

U. S. Department of Commerce

5285 Port Royal Road

Springfield, VA 22161

Price: Printed Copy $\$ 4.00$; Microfiche $\$ 3.00$ 


\section{PAGES 1 to 2 WERE INTENTIONALLY LEFT BLANK}


SAND77-1179

Unlimited Release

\section{AN INSTALLATION INDEPENDENT VERSION \\ OF THE SAIDIA SCORS PLOT SYSTEM}

\section{by}

S. L. Thompson

and

N. K. Ruiz

Sandia Laboratories

Albuquerque, New Mexico 87115

\section{ABSTRACT}

A portable version of the Sandia SCORS plot system is described. The set of computer routines is designed to accompany Sandia programs sent outside of the laboratory and can generate output for any type of plotter that might be available.

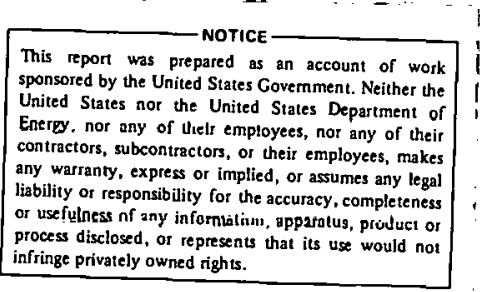




\section{CONTENTS}

I. Introduction . . . . . . . . . . . . . 7

II. How the System Is Employed . . . . . . . . . . . 9

III. User Modifications for a Particular Plot System . . . . 12

APPEIDIX

A. SUBROUTINES PLOTPR, PSETPR, PLIMPR, PLABPR . . . . . . 15.

B. DISSPLA system Calls . . . . . . . . . . . 19

C. Tektronix (PLOT 10) System Calls . . . . . . . . . 21

D. IGS System Calls . . . . . . . . . . . . 23

E. SCORS System Calls . . . . . . . . . . . 25.

F. Listing of DECK SCORC . . . . . . . . . . . 27 


\section{INTRODUCTION}

The analysis of computed data from large-scale scientific computer program often relies heavily on plot programs whose forms are highly dependent on the software available to the developers. Unfortunately, different installations use different software packages. This creates many problems for complex programs which are used at a number of installations. Each new user must start from scratch in plot code development. This invariably involves the original developer.

Most of the larger programs at SLA employ the SCORS plot system. Its output is in the SD4020 language but interpreters are available for a few other plotters. The SLA SCORS system is old but very powerful since a great deal of development effort has been put into the coding over the years. Some of the plot programs which use this SCORS system are quite. complex and took years to develop. Unfortunately, the system is available on only the CDC6600/CDC7600 machines at SLA and SLL. The proliferation of new graphic systems at Sandia in recent years, each with a different software package, has added to the difficulty.

A version of the SCORS system has been constructed for CDC host computers ( 60 bit words) to remove the installation and equipment dependence. The system can be easily transported from one installation to another and can produce output in the standard form for the new installation. The new user must supply a small amount of coding in FORTRAN for his plot system to do the four following functions:

1. Open the plot file;

2. Advance to a new plot frame and set up a plot frame (without drawing anything on the frame);

3. Draw a vector between two points on the frame defined in 2;

4. Close the plot file. 
Generally, these functions are very simple and easy for the user since they are coded in his plot system language in FORTRAN The number of FORTRAN cards required is on the order of ten. Tests have been run on a number of systems.

The plot system can also be used to generate native mode instructions for various graphic equipment but this is a more complex coding job. Only a limited number of instructions are necessary with the same general functions as previously listed.

The SD4020 has CHARACTRON characters which can cause difficulties when the output is directed to another COM unit. These characterm are produced by directing the electron beam through a screen in the CRT. When these instructions are converted to other machines, the characters must be generated by vectors. Some resolution is lost. For simple plots where resolution of these characters is not sufficient, a subroutine PLOTPR is available to remove the problem. This subroutine is not described in the SLA 4020 manual $^{*}$ but the input instructions are reproduced here in Appendix A.

The SD4020 at SLA has color capabilities. Except in one specia], case, the color instructions will be deleted in the instruction string at the Tevel SCORB in the current version. Since new COM units with color capabilities are to be added at SLA, this feature will be updated when the new equipment is available.

* "SC-4020 Usage with IBM 7090/7094, CDC 3600, UNIVAC 1108, CDC 6600," Sandia Laboratories, Albuquerque, New Mexico, SC-M-70-68, Marçh, 1970 (Revised). 
II. HOW THE SYSTEM IS EMPLOYED

The new SCORS system can be installation independent because it uses whatever plot system software is available. To illustrate, let us assume that a plot system URSYS exist on a CDC machine using a SCOPE system (i.e. CDC operating system). URSYS would normally be a library file. If URPLOT is a program (with the same permanent file name) which uses the URSYS plot package, then one usage of URPLOT might be as follows .

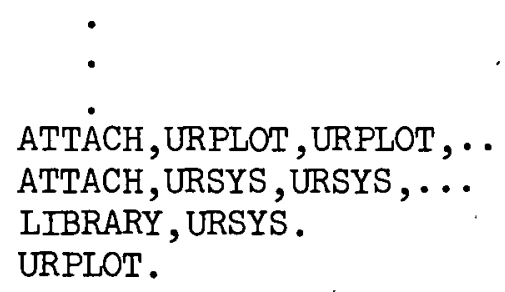

The system can be used in either of two ways. It can produce the finished plotter output file in a single execution as part of the program using the SCORS calls or a post-processing method can be used. The latter procedure is normally more efficient. The new SCORS system has five sets of subroutines or "decks" with the following names.

\section{SCORS \\ SCORPOP \\ SCORA \\ SCORB \\ SCORC}

The last of these is modified to call the current plot system URSYS. Let Uis assume a program called SLAPLT which employs the SCORS system. The following grouping would be used to produce the plots in a single execution

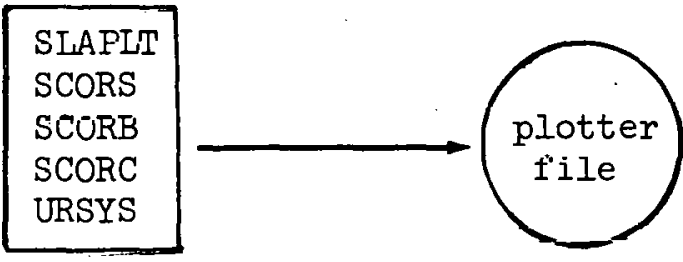


For post-processing the two executions would normally be stacked in a single job and would use the grouping

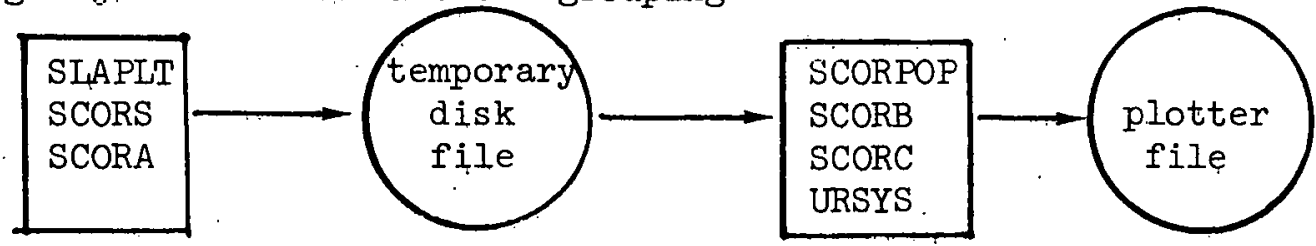

In this example, the data is transferred between the two executions on a disk or tape file. The file name is that file which SCORS would normally employ for its output to the SD4020 and is defined in SIAPLT by a call to ENTFLM or HDCOPY.

Now the above examples are illustrated uging SCOPE control statements. All decks are compiled and library files are generated as shown below (using EDITLIB on SCOPE 2.1 CDC7600 class or SCOPE 3.4 CDC6000 class machines). The files are cataloged as permanent files.

$\begin{array}{lcc}\text { UPDATE or deck file } & \text { Program file } & \text { Library file } \\ \text { SLAPLT } & \text { SLAPLT } & \\ \text { SCORS } & \text { SCORPOP } & \text { LSCORS } \\ \text { SCORPOP } & & \\ \text { SCORA } & & \text { LSCORA } \\ \text { SCORB } & \text { LSCORBC } \\ \text { SCORC } & & \text { LSCORBC }\end{array}$

It i.s assumed that UR3Y crist as a library file. The single execution would he

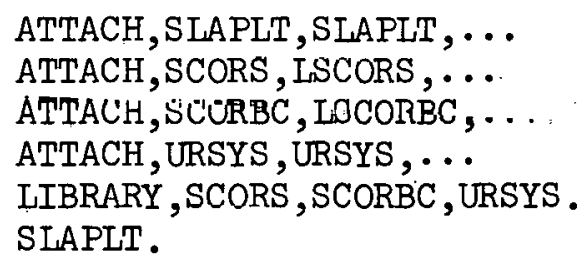

For post-processing, the output file from SLAPIT is directed to SCORPOP as the first argument on the execute card. The output file of SCORPOP is the second argument as the program is supplied. It might be necessary to modify this for each installation depending on plotter file require- 
ments. The default output name is TAPE4l. The control statements would be

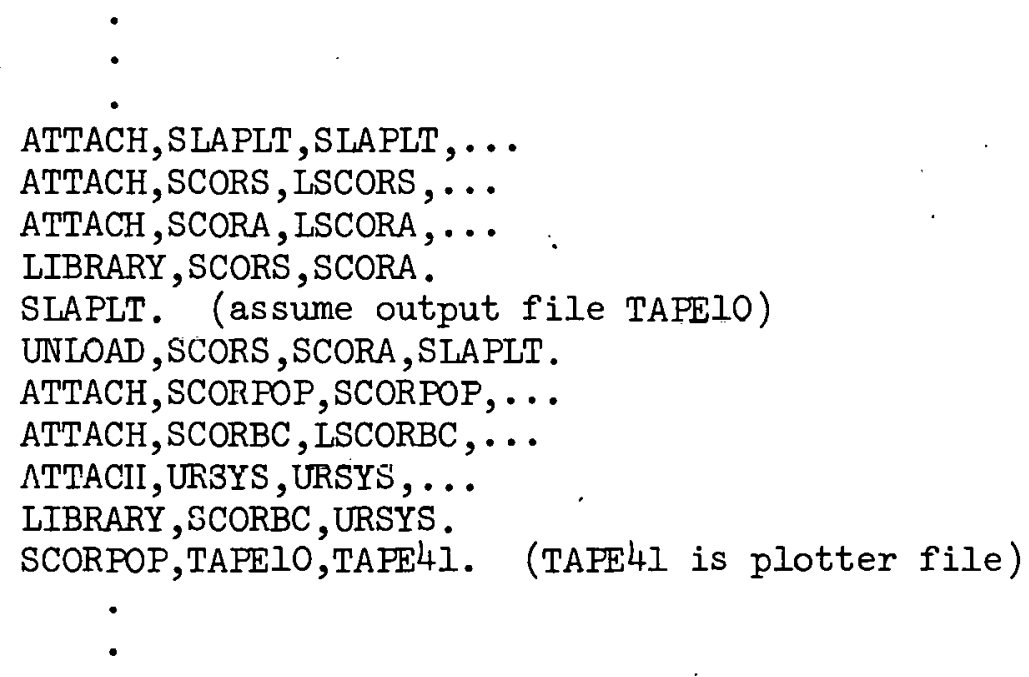

The SCORS package can produce simultaneous output files (up to 99 at one time). When post-processing this would require a separate SCORPOP execution for each f'ile. 
III. USER MODIFICATIONS FOR A PARTICUIAAR PLOT SYSTEM

All functions which the user must define are in deck SCORC. Details of the additions to the four subroutines in this deck follow. Examples for several plot systems are given in appendices.

\section{APPENDIX}

B.

C.

D.

E.
PLOT SYSTEM

DISSPIA
PLOTIO
IGS
SCORS

[for Tektronix terminals]

[for SD4460]

[for SD4020]

The deck SCnRC is listed in Appendix $F$. INITC2

This is the initialization routine to open the plot file. Any initial plot ID frames required at the installation should be added here: The output file used by the SCORS program is defined by either CALL $\operatorname{ENTFLM(NM)~or~CALL~HDCOPY~(NM)~where~NM~is~the~tape~number~(TAPENM).~The~}$ value of NM is passed to INITC2 so that this file is available for use by the now plot system. If the user's system has a fixed output unit, then the argument can be ignored except lor adalug lie filo name tin the program card.

$\underline{\text { PAGEC2 }}$

This is the frame ( $x$ page) advance command followed by the plot field definition. The plot coordinate limits are 0 to 1023 in both directions. The field of view or "window" should be squar'. No lines shn!̣ld be drawn at this point. 
$\underline{\operatorname{INEC} 2(\mathrm{X} 1, \mathrm{Y} 1, \mathrm{X} 2, \mathrm{Y} 2)}$

This is the vector drawing routine. Instructions should be inserted to draw a line from the point $(\mathrm{XI}, \mathrm{Y} 1)$ to the point $(\mathrm{X} 2, \mathrm{Y} 2)$ on the frame defined by PAGEC2. All coordinates are in the range of 0 . to 1023.0. .

$\underline{\text { EXITC2 }}$

This is the post-plotting routine which closes the plot file. Any final ID frames required for the installation should be generated here. CHARC2

The SD4020 uses a CHARACTRON character to light a point or single raster coordinate. In the current SCORS system this is treated as a short vector of length 1 (out of 1024): It was found that many plotters do not have the capability of lighting a single point or would not draw a zero length vector which one could use to reproduce this feature. After the system is operating and this short vector is found not satisfactory then the coding can easily be changed to use any feature available in the current system which will produce better results. Replace the CALL LINEC2 $(X, Y, X+E, Y+E)$ by the appropriate call to the new system. This ohould nol be attempted until the other features of the system are checked out. 
Appendix A 
SUBROUTINES PLOTPR, PSETPR, PLIMPR, PLABPR

PLOTPR is a high-level plot subroutine in the SCORS system similar to PLOTXY and AICRT3, but is more flexible than either. All lettering is large so that plots are suitable for publication and reports as produced. The small SCORS typewriter letters are not used for axis labels or numbering. Grid lines are optional. Multiple plot frames on a single 4020 frame are possible.

PLOTPR has three supporting eubroutines for optional use. PSETPR allows changes in margins, axis numbering, and grid densities. PLIMPR is available to aid the user in determining plot limits generated by the program. PLABPR can be used to generate additional labels such as figure captions.

PLOTPR usage is as follows

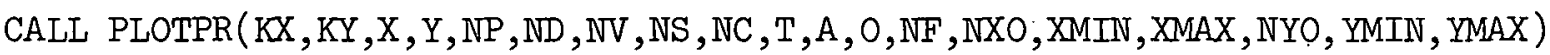

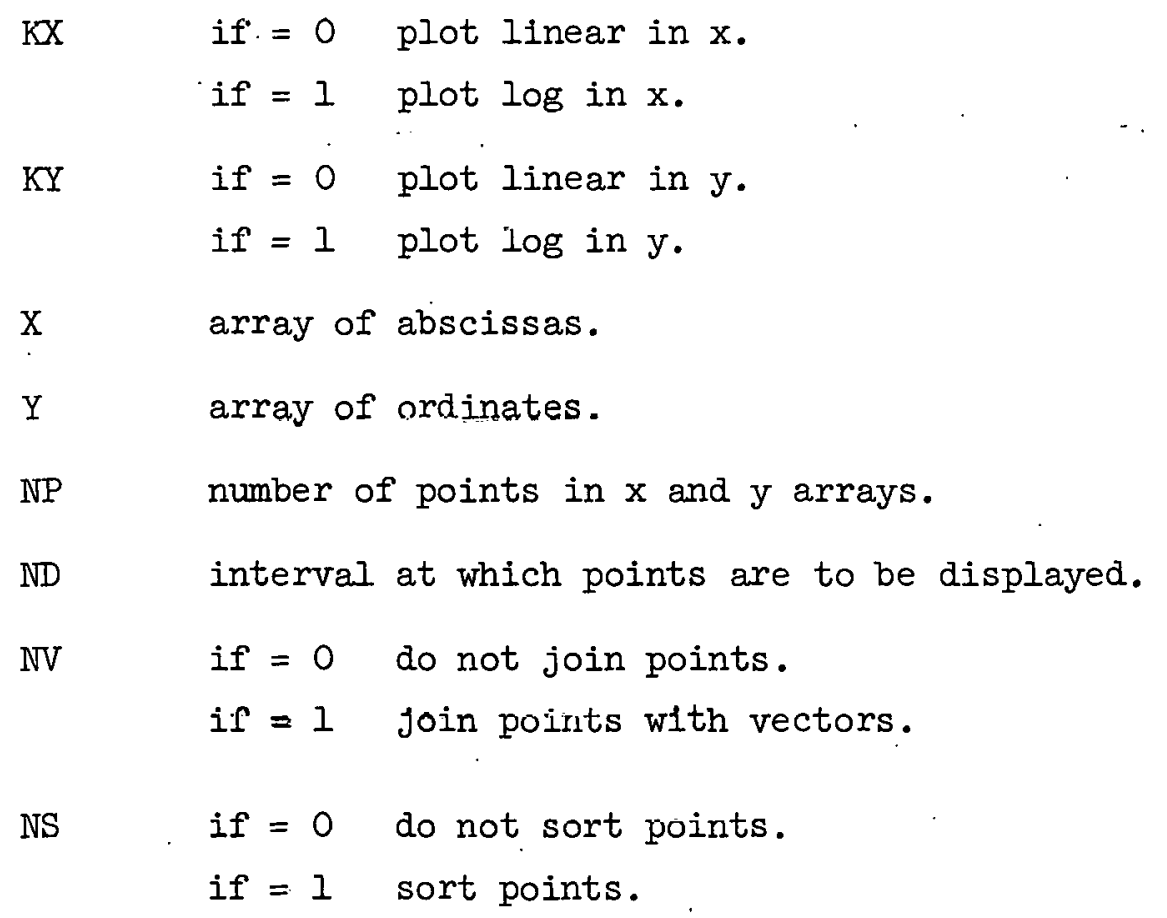




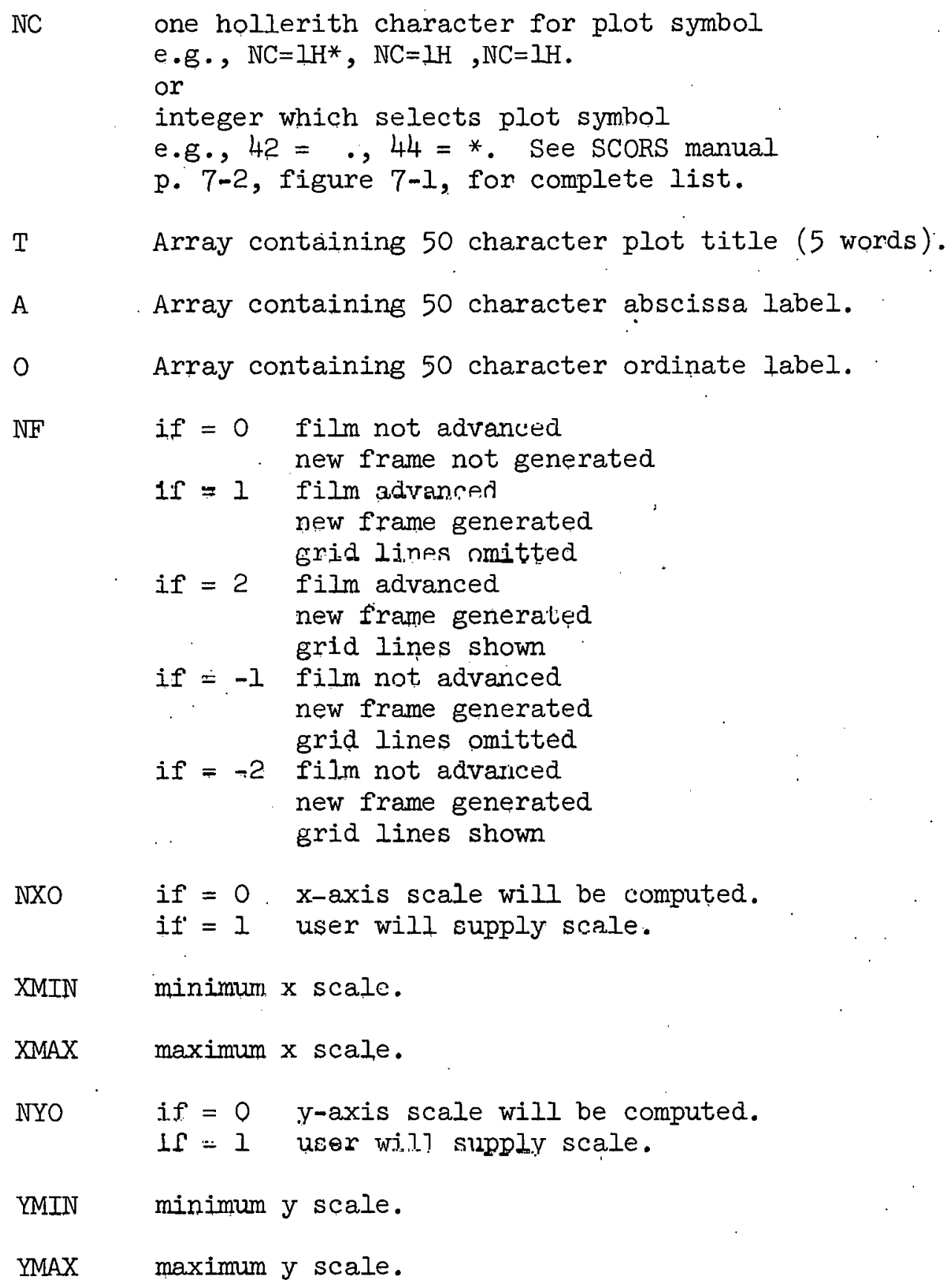


PSETPR usage is as follows

CALL PSETPR (NX,NY,ML,MR,MB,MT,MRX,MRY,NSC3)

values in ( ) are used by PLOTPR if not changed by PSETPR.

$\mathrm{NX}=$ abscissa numbering interval (2)

$\mathrm{NY}=$ ordinate numbering interval (1)

MI = left margin in rasters (0)

$\mathrm{MR}=$ right margin $(0)$

$\mathrm{MB}=$ bottom margin (0)

$\mathrm{MT}=$ top margin $(0)$

MRX = desired distance between $\mathrm{x}$ grid lines in rasters (20) used only if $\mathrm{KX}=0$ and $\mathrm{NF}=+2$ or -2 $\mathrm{MRX} \geq 10$

MRY = desired distance between $y$ grid lines in rasters (20) used only if $\mathrm{KY}=0$ and $\mathrm{NF}=+2$ or -2 MRY 220

NSC $3=0$ axis scales in powers of 1000 . (0)

floating decimal point position

$=1$ axis scales in powers of 10

fixed decimal point position

(NSC3 is only used for linear plots)

PLIMPR usage is as follows

CALL PLIMPR(XYLIM)

XYLIM is an array of 4 words returned where

$$
\begin{aligned}
& X Y L I M(1)=X M I N \\
& X Y L \perp M(2)=X M A X \\
& X Y L I M(3)=X M I N \\
& X Y L I M(4)=Y M A X
\end{aligned}
$$


PLABPR usage is as follows

CALI PLABPR( LAB1, LAB2)

LABI array contalning 70 character label(top)

LAB2 array containing 70 character label(bottom).

PLABPR call must follow PLOTPR call.

The labels are written below the plot with LABI above IAB2.

PLOTPR will not alter any of the parameters in the culling ocquense except When $\mathrm{N} 33$ - 1 which will probably result in reordering of $X$ and $Y$ arrays.

PLOTPR checks for of't' scale points when the user has supplied the scales. They will be plotted on the appropriate boundary.

If $\mathrm{NXO}=0$ or $\mathrm{NYO}=0$, the scales selected by the program are not returned in the call argument list since PLOTPR does not alter the list. They are available to the user through PLIMPR. It should be noted that if $N X O=1$, or $\mathrm{NYO}=1$, PLOTPR might extend the limits slightly from the XMIN, XMAX, YMIN, YMAX inputs.

The variable $\mathrm{NF}=0$ is used to plot adalliumal data on the last frame generated. When. $\overrightarrow{N F}=-1,-2$ a new frame is generated but the film is not advanced. This can be used to plot several graphs on a single 4020 frame in conjunction with the marg1r vuliablco of PSEITR:

The $T$, A, and $O$ arrays contain 50 characters for full size plots. If the margins are increased a smaller number of characters will be displayed. The same i.s true for ILABI and IAB2 of PLABPR.

Some resolution is lost when small size plots are generuled by margin value resets. The limits $(M I+M R),(M B+M T) \geq 683$ are built into the program. This will allow a maximum of 9 plots on a single 4020 frame. 
Appendix $B$ 


\section{APPENDIX B}

DISSPLA System Calls

DISSPLA is a plot package produced by Integrated Software Systems Corporation. The form employed here is the version which uses the postprocessor DISSPOP. DISSPLA does not have the.capability of lighting a single point.

* I SCORC. 9

*I SCURC. 22 CALL COMPRS

CALL BGNPL $(-1)$

DATA XYZ / $/ \mathrm{H} /$

CALL ENDPT(O)

CALI, PAGE(11.,11.)

CALL PHYSOR $(0 ., 0$.

CALL TITLE (XYZ,I,XYZ, 0,XYZ, 0,11.,11.)

*I SCORC.33

CALL $\operatorname{GRAF}(0 ., 1023 ., 1023 ., 0 ., 1023 ., 1023$.

*I SCORC. 42

DATA SX /10.752688E-3/

DATA SY $/ 10.752688 \mathrm{E}-3 /$

CALL STRTPT (SX*XI,SY*YI)

CALL CONNPT (SX*XZ, SY*Y2)

CALL INDPL(O)

CALL DONEPLL 
Appendix C 
APPENDIX C

Tektronix (PLOT10) System calls

PLOTlO is a Tektronix plot package. The single raster plot feature

is the last of the following inserte.

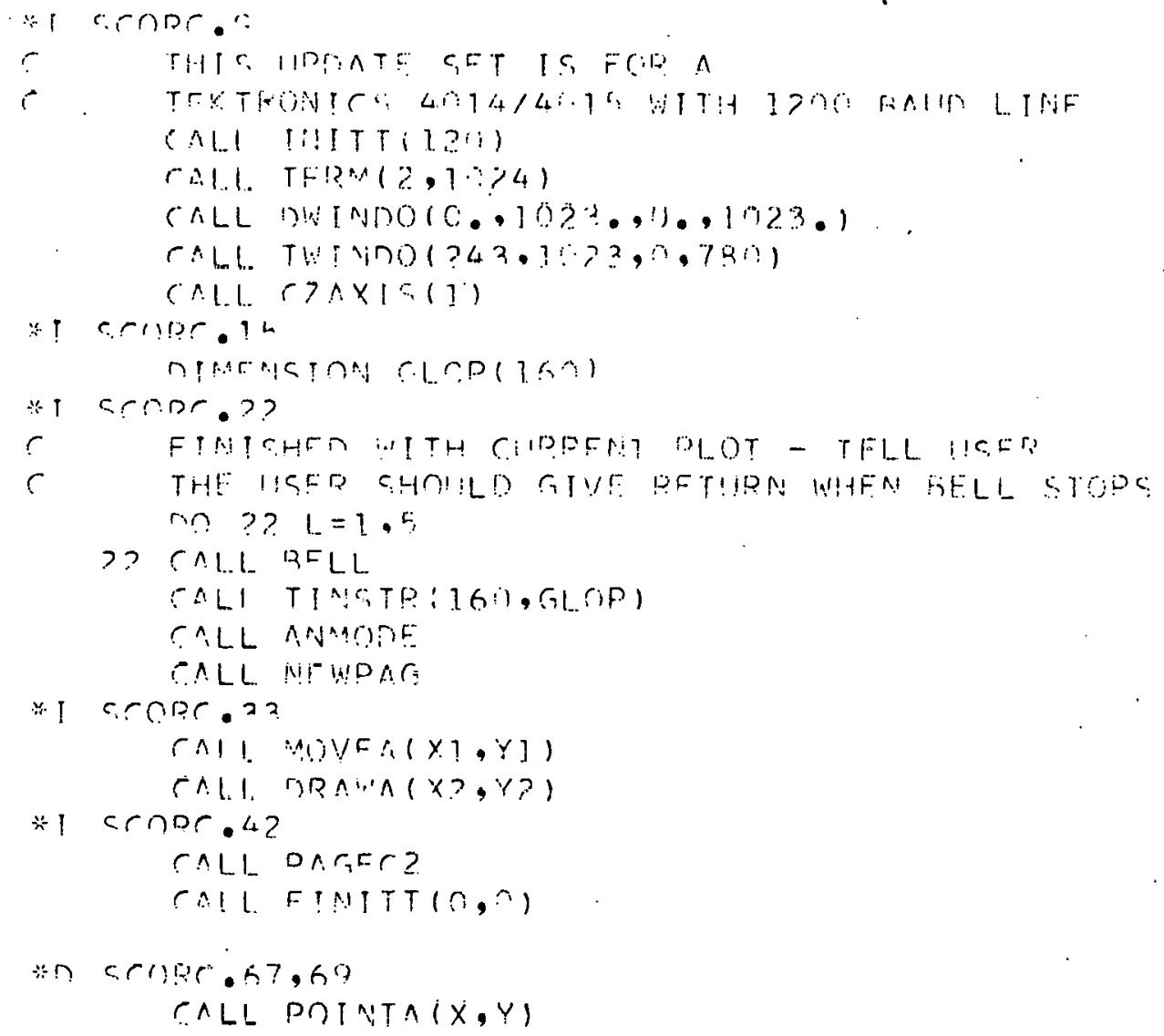

22 
Appendix D 


\section{APPENDIX D}

\section{IGS System Calls}

The IGS plot package produces native mode instructions for the SD4060/4460. The plot frame is rectangular with 3572 by 4096 rasters. The single raster plot feature is the last of the following inserts.

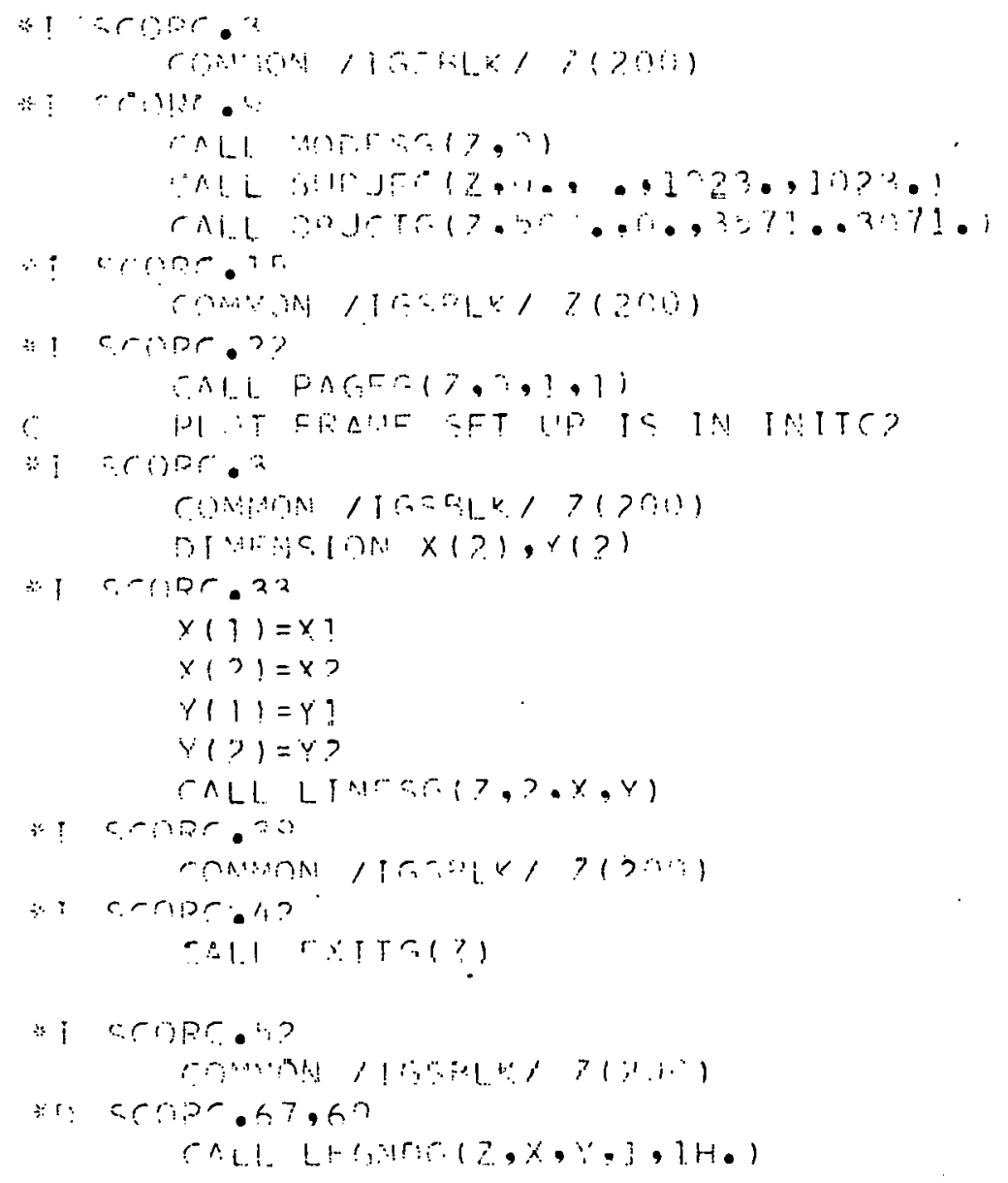


Appendix E 


\section{Appendix $E$}

SCORS System Calls

This system can only be used in the post-processor form. It is a special case and would be useful in directing output to two plotters at once, for example, a NOS Tektronix terminal and batch hard copy.

This option will properly treat SD4020 color instructions using the CALL ENTFLM(KOUT) option instead of CALL HDCOPY(KOUT).

Much of the data in the inpul file for the post-processop is already. in SD4020 machine language. This can be used to speed the processint by replacing the CALL PLOTC2(N(I)) in SCORPOP by CALI PLOIDU(N(I)). The deck SCORB is then not required, i.e. the post-processor is formed from SCORPOP and SCORC only. The rest of the correction set is as follows

*I SCORC. 9

*I SCORC. 22

*I SCORC.33

$$
\text { CALL HDCOPY(KOUT) }
$$

CALL FRAMEV(3)

$\mathrm{IXI}=\mathrm{XI}$

$T Y I=Y I$

IX2-X2

$\mathrm{IY} 2=\mathrm{Y} 2$

*I SCORC. 42

CALL LINEV(IX1, IY1, IX2, IY2)

*i) ScokC 48,73

CALL EXTFLM(O) 
APPENDIX F

Listing of DECK SCORC 
SUERTUTINE. INITC2 (ITOUT) SCOFC

SCOFC

SCOPC

SCOFC

SCOFC

SCOFC

SCOFC

SCOFC

SCOFC

SCOFC

SCOFC

SCOFC

SCOFC 


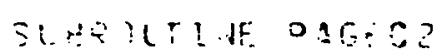

SCOFC

SCOFC

SCOFC

the

SCO 50

SCOFC

SCOFC

SCOFC

TATA RFQISI

CALL YOU? POJTINES HE?E

SCOFC

SCOFC

SCOFC

SCOFC

INTR IS FRAME COUNT

$560 \% C$

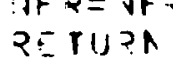

C. SOCEJ TOV. 1375 GY HANCY RUIZ, ORG.E1EG, SANJIA LAECRATJFIFS,

SCOFC

SCOFC

SCOFC 
SURROLIINE LINECE $(X 1, Y 1, X 2, Y \geq)$

$D R E W$ A LINE FROM $X_{1}, Y_{1}, Y_{O} X_{2}, Y_{2}$

SCOFC

SCOFC

SCOFC

SCOFC

SCOFC

SCOFC

RETURA

SCOFC

COCE! YOV. 1975 BY NANCY RUIZ, ORG.5165, SANOIA LABCPATOFIES,

SCOFC

SCOFC ENS 


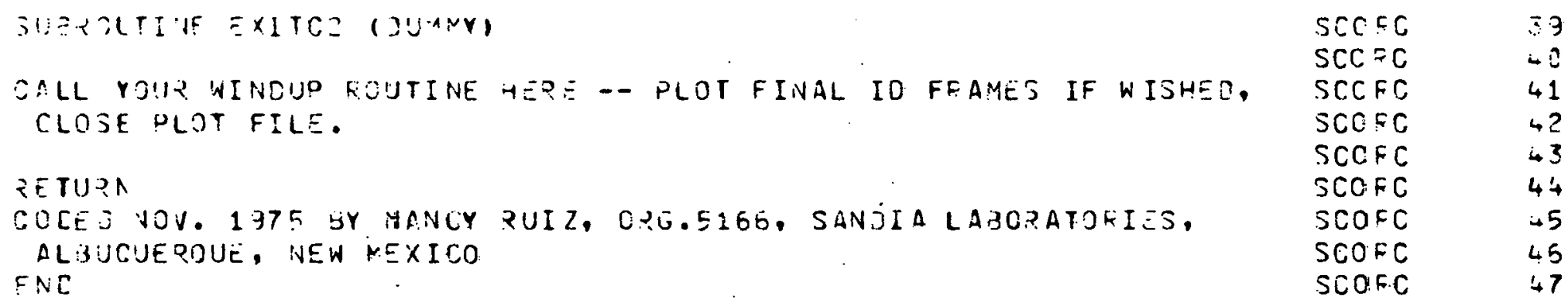


SUBRUUTINE CHARCE (X,Y, KHAR)

SCORC

SCOFC

SCOFC

OISPLAY CHAZACTER KHAZ AT POIN- (X,Y)

SCOFC

SEE SANDIA DOCUMENT SC-M-7J-68,P.2-9 FOR THE SD 4020

CHARACTE $=$ SET.

EXTECRALL TABLIV

DIMENSION EX(4), EY (4)

DATA EX,EY,IEXY $10,1,0,0,1, .1,0,0-1,0,0,1$,

TEST FOR SLANK

IF (KHAR.EQ.48) GO TC 20

C TEST FOP CENTERED PEFICD

IF $(K H A R, E Q .42)$ GO TE 10

I $X=X-3$.

I $Y=Y-4$.

CALL VCHRC2 IIX, IY,KHAR, TABL IV)

GO TO 20

1O CONTINUE

$\mathrm{C}$

CENTERED PERIOD DRAWN WITH SHOFT ROTATING VECTOR

SCOFC 52

SCOFC 53

SCOFC 54

SCOFC $\quad 55$

SCOFC 56

SCOFC 57

SCOFC 58

SCOFC $\quad 59$

SCOFC 60

SCOFC $\quad 61$

SCOFC 62

SCORC $\quad 6.3$

SCOFC $\quad 64$

SCORC 65

CARDS WITH POIAT CALL IF YOUR HAVE ONE

SCOFC

CALL LINEC? $(X, Y, X+E X$ (IEXY), Y+EY (IEXYY) IEXY = IEXY+1

20

IF (IEXY.GE.5) I EXY $=1$

SCOFC 67

SCOFC 69

SCOFC 69

SCORC 7?

$x+3$

C GODED BY S.THOMPSON DIV 5166 SLA JUNE,1977.

SCOFC $\quad 71$

SCOPC 72

ENC

SCOFC 


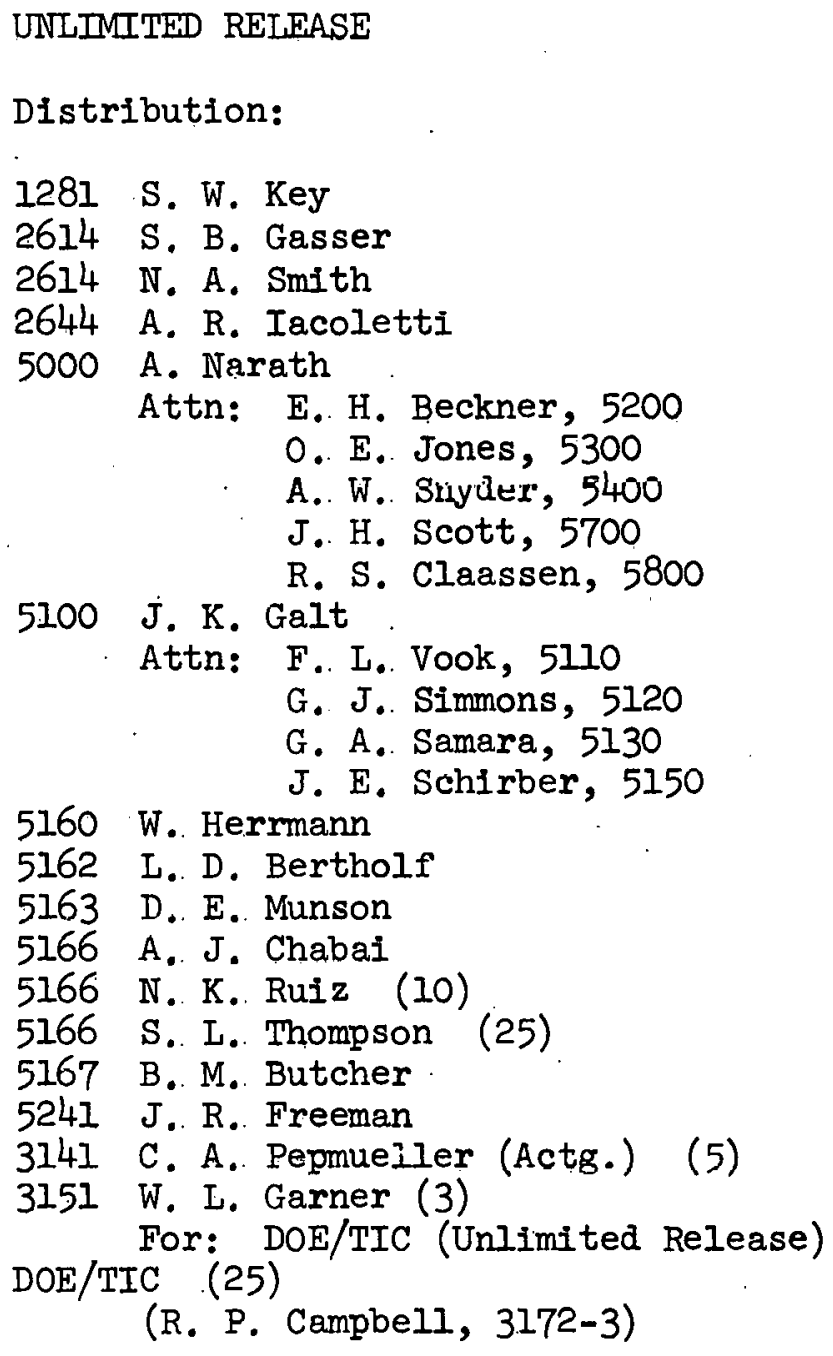

